\title{
Nutrisyonel Risk Değerlendirme Ölçeklerinin İstatistiksel Testlerle Karşılaştırılması
}

\author{
DOI: 10.26466/opus.523493 \\ * \\ $\underline{\text { Selim Gündüz }}$ - Dilek Doğan** ${ }^{* *}$ Ezgi Bayraktar*** \\ * Dr. Öğr. Üyesi, Adana Bilim ve Teknoloji Üniversitesi, İşletme Fakültesi, Adana/Türkiye \\ E-Posta: sgunduz@adanabtu.edu.tr ORCID: 0000-0001-5289-6089 \\ ** Dyt., Adana Şehir Eğitim ve Araştırma Hastanesi, Beslenme ve Diyet Bölümü, Adana/Türkiye \\ E-Posta: dilek.dogan3@saglik.gov.tr ORCID: 0000-0001-6988-9547 \\ *** Dyt., Adana Şehir Eğitim ve Araştırma Hastanesi, Beslenme ve Diyet Bölümü, Adana/Türkiye \\ E-Posta: ezgi.bayraktar@saglik.gov.tr ORCID: $\underline{0000-0002-7450-4370}$
}

\section{$\ddot{O} z$}

Bu çalışmanın amacl, yatan hastaların nütrisyon risk değerlendirmesinde günümüzde yaygın olarak kullanulan Malnütrisyon Universal Tarama Aracı - MUST (Malnutrition Universal Screening Tool) ve Nutrisyonel Risk Tarama Aract - NRS 2002 (Nutritional Risk Screening 2002) beslenme tarama ölçeklerinin sonuçlarının istatistiksel olarak karşılaştırılması ve aralarındaki uyumun araștırılmasıdır. Çalışma, T.C. Sağlık Bakanlığı Adana Şehir Ĕ̆itim ve Araştırma Hastanesi'nde tedavi görmekte olan 20 ile 90 yaş arası, 124'ü erkek, 96'sı kadın olmak üzere toplam 220 hasta ile gerçekleştirilmiştir. Katılımcılara uygulanan anket formunda, demografik sorular, antropometrik ölçümler ve NRS-2002 ile MUST beslenme tarama ölçeklerinde bulunan sorular yer almaktadır. Bireylerin beslenme durumlarının dă̆̆lımı açısından NRS-2002 ve MUST testleri arasında uyum olup olmadığı Kappa analizi ile test edilmiştir. Beslenme tarama ölçeklerinden elde dilen sonuçlar ile hastaların demografik özellikleri arasında istatistiksel olarak anlamlı bir farklılı̆̆ın bulunup bulunmadığg da parametrik olmayan istatistiksel yöntemlerden Mann Whitney U ve Kruskal Wallis testleriyle analiz edilmiştir. Bireylerin beslenme durumlarının dağılımı açısından NRS-2002 ve MUST testleri arasında Kappa testinden elde edilen sonuçlara göre istatistiksel olarak anlaml bir uyum bulunmuştur $(\mathrm{k}=0,358, p<0,01)$. Ayrıca, NRS-2002 skorları arttıkça MUST skorlarında da bir artış gözlemlenmiş ve dolayısıyla aralarında pozitif yönlü orta düzeyde bir ilişki olduğu belirlenmiştir $(r=0,592, p<0,01)$. Sonuç olarak bireylere uygulanan NRS-2002 ve MUST beslenme tarama testleri arasında bu çalışmada kullanulan örneklem için pozitif yönde bir korelasyonun olduğu ve istatistiksel olarak da anlaml bir uyumun bulunduğu görülmüştür.

Anahtar Kelimeler: Nutrisyonel risk, NRS-2002, MUST testi, Kappa analizi 


\title{
Comparison of Nutrision Risk Assessment Scales with Statistical Tests
}

\begin{abstract}
The aim of this study is to compare the results of MUST (Malnutrition Universal Screening Tool) and NRS-2002 (Nutritional Risk Screening 2002) nutritional screening scales which are widely used in nutritional risk assessment of inpatients and to investigate the harmony between them statistically. This study was carried out with a total of 220 people (124 male, 96 female) between the ages of 20 and 90 who were being treated in Republic of Turkey Ministry Of Health Adana Provincial Health Directorate Adana City Training and Research Hospital. Questionnaires applied to the participants include demographic questions, anthropometric measurements and questions found on the NRS-2002 and MUST nutrition screening scales. The Kappa analysis was used to determine whether there was a correlation between NRS-2002 and MUST tests for the distribution of nutritional status of individuals. In addition, the results obtained from dietary screening scales and whether there was a statistically significant difference between the demographic characteristics of the patients were analyzed with non-parametric statistical methods, Mann Whitney $U$ and Kruskal Wallis tests. A statistically significant correlation was found between NRS-2002 and MUST tests in terms of distribution of nutritional status of individuals according to Kappa test results $(\mathrm{K}=0,358, p<0,01)$. Furthermore, as the NRS-2002 scores increased, an increase in MUST scores was observed and a positive correlation was observed between them $(r=$ $0.592, p<0.01)$. As a result, there was a positive correlation between NRS-2002 and MUST nutrition screening tests applied to individuals and there was a statistically significant correlation between the samples used in this study.
\end{abstract}

Keywords: Nutritional Risk, NRS-2002, MUST test, Kappa Analysis 


\section{Giriş}

Günümüz dünyasında yetersiz beslenmenin ve tüketilen yanlış besin maddelerinin insan sağlığı üzerindeki olumsuz etkileri daha net anlaşılmaktadır. Doğru beslenmemenin insan sağlığ üzerinde yarattığ olumsuzluklar, toplumda manevi bozukluklar oluşturmasının yanında maddi olarak da ülke ekonomisini ve sağlık alanındaki hizmet kalitesini etkilemektedir. Bundan dolayı özellikle gelişmiş ülkelerin ilgili birim yöneticileri kendi sınırlarında üretilen veya ithal edilen besin maddelerinin güvenilirlik kontrollerini azami ölçüde artırmış, bunun yanı sıra okul, hastane, çocuk ve yaşlı bakımevleri gibi çeşitli kurumlarda da yeterli ve dengeli beslenme programları hazırlatmışlardır.

Beslenmenin bireyleri hastalıklardan korumasının yanı sıra tedavi sürecinde de hastalığın seyri açısından büyük önem taşıdığ1 bilinmektedir. Özellikle ağır hastalık geçiren bireylerde hastalığın kendisi ve uygulanan tedaviler çeşitli düzeyde beslenme bozukluklarına neden olabilmektedir. Bu beslenme bozuklukları için önlem alınmadığında ise hastaların tedavi süreçleri olumsuz etkilenmekte, yaşam kaliteleri düşmekte hatta ölüm riskleri artmaktadır. Çünkü bu tür hastalarda gelişen malnütrisyon, iyileşme sürecini geciktirmekte, dolayısıyla hastanede kalış süresini uzatmakta, vücudun bağışıklık sistemini zayıflatmakta ve enfeksiyonlara neden olmaktadır (Kaya, 2015).

Malnütrisyon, aşırı beslenmiş kişiler için de kullanılabilmesine karşın yaygın olarak yetersiz beslenmiş hastalar için kullanılan bir terimdir (Bolayır, 2014). Avrupa Parenteral ve Enteral Beslenme Derneği (ESPEN European Society for Parenteral and Enteral Nutrition) malnütrisyonu, yetersiz veya düzensiz beslenmenin neden olduğu, vücut kompozisyonunun ve vücut hücre kitlesinin bozulması sonucu ortaya çıkan fiziksel ve mental fonksiyonların azalması ve hastalığın klinik sonucunun kötüleşmesi durumu olarak tanımlamaktadır (Sobotka ve Allison, 2011). Tek başına açlık, hastalık, yaşlanma veya bunların kombinasyonları sonucunda malnütrisyon durumu gelişebilmektedir (Pirlich ve ark., 2005). Ayrıca, hastaneye yatırılan hastaların yetersiz beslenmeye dayalı ya da herhangi bir hastalığının sonucu olarak malnütrisyonda olması tedavi sürecini uzatacak ve negatif yönde etki edecektir. Bu da gerek ekonomik olarak gerekse de sağlik sektöründe 
oluşturacağ1 yoğunluk nedeniyle topluma önemli bir yük getirecektir (Gündoğdu, 2010).

Türkiye'de yatan hastalardaki malnütrisyon sıklığı ile ilgili yeterince veri olmadığı veya kolay bir ulaşımın sağlanamadığı görülmekle birlikte yapılan çalışmalarda hastaneye kabul anında hastalardaki malnütrisyon oranının \%5-60 arasında olduğu, aynı zamanda malnütrisyon sıklığının bütün yaş gruplarında azımsanmayacak düzeyde olmasına rağmen, 65 yaş ve üzeri yaş grubunda daha yüksek olduğu gösterilmiştir. Yine bu alandaki ilgili çalışmalar incelendiğinde, yoğun bakım hastalarında ve medikal onkolojiye başvuran hastalarda diğer birimlere başvuran hastalara göre riskin daha yüksek olduğu görülmüştür (Kaya, 2015, Norman ve ark., 2008, Sungurtekin ve ark., 2004, Korfalı ve ark., 2009, Lim ve ark, 2012).

Hastalarda komplikasyon gelişmesini, hastanede yatış süresini ve ölüm riskini düşürebilmesi için beslenme değerlendirmeleri yapılmalı ve yetersiz beslenme durumu tespit edildiğinde gerekli önlemler alınmalıdır. Bireylerin beslenme durumlarını tespit etmeye yönelik olarak pek çok tarama aracı, antropometrik ölçümler ve laboratuvar testleri gibi yöntemler kullanılmaktadır (Pekcan, 2011). Hastaların durumuna, zamana, ekonomik koşullara, eğitimli personele veya mevcut koşullara göre bu tarama ölçeklerinden uygun olanları kullanılarak tüm kamu hizmetindeki huzurevleri, bakımevleri ve hastanelerdeki hastaların beslenme durumlarının tespit edilip, malnütrisyon risklerinin ölçülmesi ve gerekli beslenme müdahalelerinin yapılması erken önlemlerin alınabilmesi açısından büyük önem arz etmektedir (Gündoğdu, 2010).

Malnütrisyon risk taraması, nutrisyonel riski tanımlamak için yapılan hızlı bir işlemdir ve sağlık kurumlarına başvuran tüm olgularda uygun, doğrulanmış bir araç kullanılarak yapılmalıdır. Beslenme desteği kavramının gündeme geldiği günden bugüne çeşitli beslenme değerlendirme araçları kullanılmıştır (Dervişoğlu ve ark., 2006). Ancak, dünya genelinde herkes tarafından kabul edilen, en uygun tarama arac1 denilebilecek bir ölçek olmaması ile birlikte, özellikle yatan hastalarda kullanılması tavsiye edilen pek çok tarama araçları mevcuttur (Bolayır, 2014). Örneğin, Avrupa Parenteral ve Enteral Beslenme Derneği (ESPENEuropean Society of Parenteral and Enteral Nutrition) bu araçlardan Nutrisyonel Risk Taraması (NRS 2002-Nutrition Risk Secreening 2002) ve 
Malnütrisyon Evrensel Tarama Aracı (MUST-Malnutrition Universal Screening Tool) ölçeklerinin kullanımını tavsiye etmektedir (Kondrup ve ark., 2003, Bendich, 2009). Bu tarama araçlarının yanı sıra, MNA (Mini Nutritional Assessment), SNAQ (Short Nutritional Assessment Questionnaire) ve SGA (Subjective Global Assessment) gibi tarama araçları da mevcut olup, bunlarla birlikte hastanın öyküsü, antropometrik ölçümler ve biyokimyasal parametreler de beslenme durumunun saptanması ve nutrisyonel değerlendirmede kullanılmaktadır (Cederholm ve ark., 2010). Nütrisyonel değerlendirme, malnütrisyon tedavisinin ilk basamağıdır ve hastanın metabolik durumuna ilişkin değerlendirme de nütrisyonel duruma ilişkin değerlendirme ile birlikte yapılmalıdır (Yentür, 2011). Ancak unutulmamalıdır ki hiçbir test malnütrisyon riskinin derece ve tipini belirlemek için tek başına yeterli değildir (Kömürcü, 2004).

Nütrisyonel Risk Taraması - NRS 2002 beslenme tarama aracı, 2002 yılında Kondrup ve çalışma arkadaşları tarafından, Danimarka Parenteral ve Enteral Nutrisyon topluluğunun katkılarıla geliştirilmiştir (Kondrup ve ark., 2003). Başak Bolayır (2014) tarafından ise cerrahi ve dâhiliye servislerindeki 271 hasta üzerinde gerçekleştirilen bir çalışma ile ölçeğin Türkçe geçerlik ve güvenirliği yapılmıştır. Bu tarama aracı ile bireylerin yetersiz beslenme düzeylerinin ve malnütrisyon risk oranlarının belirlenmesi amaçlanmaktadır. Bu ölçekte ilk olarak bireylere bir ön tarama testi uygulanmaktadır. Ön tarama testinde bireye VKİ değerinin $20,5 \mathrm{~kg} / \mathrm{m}^{2}$ den az olup olmadığı, son 3 ayda kilo kaybı yaşayıp yaşamadığı, son hafta gıda alımında azalma olup olmadığ ve hastanın durumunun ağır olup olmadığı sorulur. Bu sorulardan en az birine evet cevabı alındığı takdirde esas tarama kısmına geçilir, eğer tüm sorulara hayır cevabı verilirse belirli periyotlarla ön tarama tekrarlanır. Ölçeğin esas tarama kısmında ise bireylerin beslenme durumundaki düzensizlik ve hastalık şiddeti ölçülmektedir. Kilo kaybının yüzdesine göre beslenme durumundaki düzensizlik; yok (0 puan), hafif (1 puan), orta (2 puan) ve ağır (3 puan) şeklinde değerlendirilir. Hastalık şiddeti ise; yok (0 puan), hafif ( 1 puan), orta ( 2 puan) ve ağır ( 3 puan) olmak üzere beslenme durumundaki düzensizlik ile benzer şekilde değerlendirilir. Esas tarama kısmından elde edilen skorlar toplanır ve eğer birey yetmiş yaş üzerinde ise puanlamaya ek olarak yaş nedeniyle 1 puan daha eklenerek toplam 
skor bulunmuş olur. Eğer toplam skor 3 ve üzerinde ise hastada beslenme riskinin mevcut olduğu kanısı oluşur ve beslenme planı uygulanır, toplam skor 3'ün altında ise tarama testi belirli periyotlarla tekrarlanır.

Malnutrisyon Universal Tarama Arac1 - MUST testi, ESPEN derneğinin yanı sıra, İngiltere Parenteral ve Enteral Beslenme Derneği (BAPEN British Association for Parenteral and Enteral Nutrition) tarafindan da tavsiye edilen, özellikle yetişkinlerdeki obezite ve malnütrisyon riskini saptamaya yönelik olarak kullanılan bir tarama aracıdır. MUST testi kullanımı yönünden pratik ve hızlı sonuçlar verdiğinden dolayı, her ne kadar toplumdaki yaşlı bireylerin malnütrisyon riskini belirlemeye yönelik olarak geliştirilmiş olsa dahi günümüzde hastane ve bakımevlerinde yaygın olarak kullanılmaktadır (Bendich, 2009). Bu testte ilk adım olarak bireylere VKİ (Vücut Kitle İndeksi) değerlerine göre skorlar verilir. $V K \mathrm{I}>30$ ise obez kabul edilir, $V K \mathrm{I}>20$ ise 0 skoru, 18,5< $V K \mathrm{I} \leq 20$ ise 1 skoru, $V K \mathrm{I}<18,5$ ise 2 skoru). İkinci adımda son 3-6 ayda yaşanan kilo kaybına göre skorlar verilir (kilokaybı $<\% 5$ ise 0 skoru, $5 \leq$ kilokaybı $<\% 10$ ise 1 skoru, kilokaybı $\geq \% 10$ ise 2 skoru). Üçüncü adımda ise bireyde akut hastalık varsa ya da 5 günden daha uzun süreli besin alamama veya olasılığ 1 varsa 2 skoru, bunlar yoksa da 0 skoru verilir. Sonrasında ise bireylere ilk 3 adımda verilen skorlar toplanarak, toplam malnütrisyon riski hesaplanır. Toplam skor 0 ise bireyin malnütrisyon riski düşük, 1 ise malnütrisyon riski orta, 2 ve üstü ise malnütrisyon riski yüksek olarak tanımlanır ve bu risklere göre nütrisyon tedavisi ve yönetimi önerilir (Elia, 2003).

$\mathrm{Bu}$ çalışmada da, genel cerrahi ve kardiyovasküler cerrahide yatan hastaların beslenme durumlarının değerlendirilmesi, risk faktörlerinin incelenmesi ve malnütrisyon değerlendirmesinde kullanılan NRS 2002 ve MUST tarama araçlarının karşılaştırılması ve aralarındaki uyumun derecesinin tespit edilmesi hedeflenmiştir.

\section{Gereç ve Yöntem}

Çalışma, T.C. Sağlık Bakanlığı Adana Şehir Eğitim ve Araştırma Hastanesi Kalp Damar Cerrahisi ve Genel Cerrahi kliniklerinde yatarak tedavi görmekte olan 20 ile 90 yaş arası, 124'ü erkek, 96'sı kadın olmak üzere toplam 220 hasta ile gerçekleştirilmiştir. Çalışmanın amacı; cerrahi 
kliniklerinde operasyon öncesi ve sonrası hastaların beslenme durumunu iki farklı beslenme tarama aracı [Malnütrisyon Universal Tarama Aracı (MUST) ve Nutrisyonel Risk Tarama-2002 (NRS-2002)] ile saptamak, tarama araçları arasındaki uyumu ölçmek ve hastaların malnütrisyon durumunu tanımlamaktır. Çalışmanın başında hastalara araştırma hakkında bilgi verilmiş ve gönüllü olan hastalar örnekleme alınmıştır. Araştırma için 26.09.2018 tarih, 288 sayılı karar ile "Adana Şehir Eğitim ve Araştırma Hastanesi Klinik Araştırmalar Etik Kurulu"ndan onay alınmıştır. Katılımcılara uygulanan anket formunda, demografik sorular (cinsiyet, yaş vb.), antropometrik ölçümler (boy, kilo vb.) ve NRS-2002 ile MUST beslenme tarama ölçeklerinde bulunan sorular yer almaktadır. Bireylerin beslenme durumlarının dağılımı açısından NRS-2002 ve MUST testleri arasında uyum olup olmadığ Kappa analizi ile test edilmiştir. Ayrıca beslenme tarama ölçeklerinden elde edilen sonuçlar ile hastaların demografik özellikleri arasında istatistiksel olarak anlamlı bir farklılığın varlığı da Mann Whitney $U$ ve Kruskal Wallis testleriyle analiz edilmiştir.

\section{Bulgular}

Çalışmaya katılan 220 bireye ait cinsiyet ve yaş gruplarının dağılımı Tablo 1'de sunulmuştur. Çalışmada hastaların yaş ortalaması 53,75 olan 124 $(\% 56,4)$ erkek ve yaş ortalamaları 53,09 olan $96(\% 43,6)$ kadın bulunmaktadır. Bireylerin \%74,5'i 65 yaşından küçük yaş gruplarında iken, \%25,5'i 65 yaş ve üzerindedir. Cinsiyete göre yaş dağılımları incelendiğinde erkeklerin $\% 25,8$ 'inin, kadınların ise $\% 25$ 'inin 65 yaş ve üzeri yaş grubunda olduğu görülmektedir. Cinsiyete göre yaş grupları açısından bir farkın

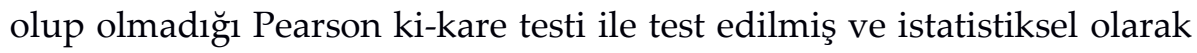
anlamlı bir farklılık bulunamamıştır ( $p=0,988>0,05)$.

Dünya Sağlık Örgütü (WHO)'nün yetişkinlerdeki vücut kitle indeksi (VKI) değerlendirme kriterlerine göre, bu çalışmadaki erkeklerin \%4'ünün kadınların ise \%1'inin zayıf olduğu $(V K \dot{I}<18,5)$ görülmüştür (Tablo 1). VKİ grupları arasında bireylerin cinsiyetleri açısından farklılık gösterip göstermediği olabilirlik oran testi ile analiz edilmiş ve aralarında istatistiksel olarak anlamlı bir farklılık olduğu tespit edilmiştir ( $p=$ 0,001). Bu farkın nereden kaynaklandığını belirlemek amacıyla yapılan 
çoklu karşılaştırmalara göre, 'şişman' olarak ifade edilen değer aralığındaki kadınların oranının erkeklere göre daha yüksek olduğu bulunmuştur. VKİ azaldıkça malnütrisyon ve malnütrisyon riski artmaktadır. Ancak cilt altı doku ödemi varlığında bu veri yanıltıcı olacaktır (Bonnefoy ve ark., 2002).

Çalışmaya katılan bireylerin tedavi görmekte oldukları birim "Genel cerrahi" ve "Kardiyovasküler cerrahi" olarak iki ayrı grupta değerlendirilmiştir. Genel cerrahi ile ilgili hastalığı olan erkeklerin oranı \%34,5, kadınların oranı \%32,7 iken kardiyovasküler cerrahi biriminde tedavi gören erkeklerin oranı $\% 21,8$, kadınların oranı ise $\% 10,9$ olarak Tablo 1'de sunulmuştur.

Tablo 1. Hastalarn cinsiyetlerine göre yaş, VKİ ve tedavi gördükleri birimlerin dăğılımı

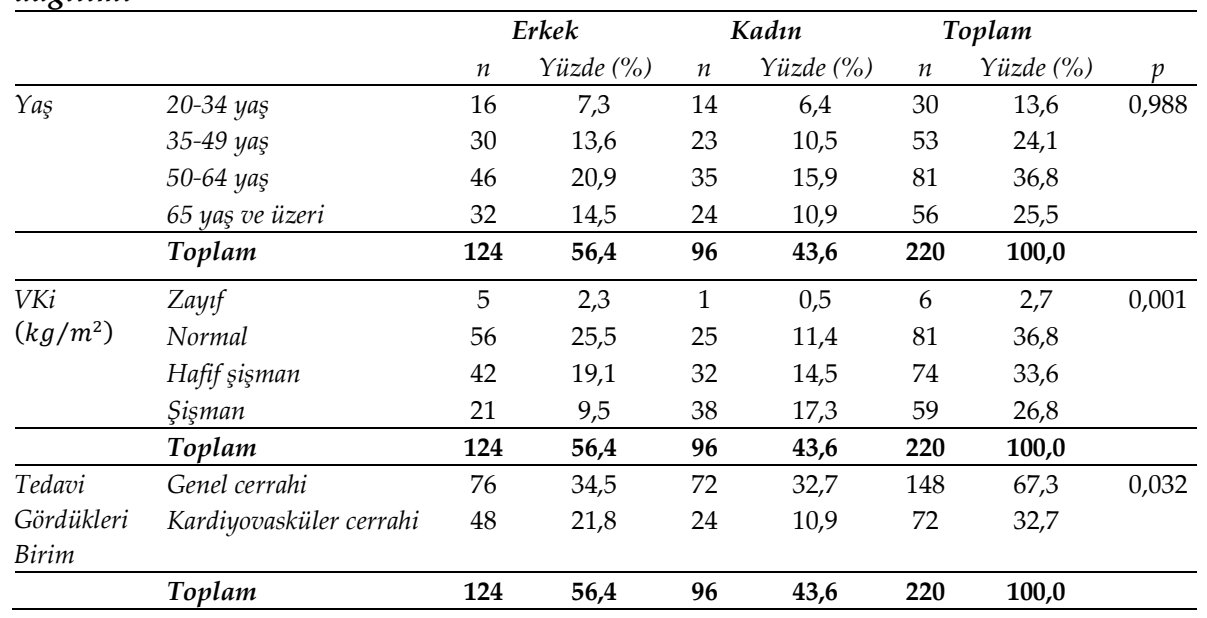

Tablo 2'de hastaların yaş gruplarına göre VKİ ve tedavi gördükleri birimler yer almaktadır. 20-34 yaş aralığındaki bireylerin \%0,5'i, 35-49 yaş aralığındaki bireylerin \%1,4'ü, 65 yaş ve üzeri bireylerin ise $\% 0,9^{\prime} \mathrm{u}$ zayıftır. VKİ grupları arasında bireylerin yaş grupları açısından farklılık gösterip göstermediği olabilirlik oran testi ile analiz edilmiş ve aralarında istatistiksel olarak anlamlı bir farklılık bulunamamıştır $(p=0,475>$ $0,05)$.

Çalışmada genel cerrahi biriminde tedavi gören hastalar, toplam bireylerin \%67,3'ünü $(n=148)$, kardiyovasküler ile ilgili hastalığ1 olanlar ise 
$\% 32,7^{\prime} \operatorname{sini}(n=72)$ oluşturmaktadır (Tablo 2). Genel cerrahi kliniklerinde tedavi görmekte olan hastaların $\% 20,9^{\prime}$ u $(n=31) 65$ yaş ve üzerinde bulunmaktadır. Kardiyovasküler cerrahi kliniklerinde tedavi görmekte olan hastaların ise $\% 34,7^{\prime} \operatorname{si}(n=25) 65$ yaş ve üzeri yaş aralığındadır.

Tablo 2. Hastaların yaş gruplarının VKİ ve tedavi gördükleri birimlere göre dağılımı

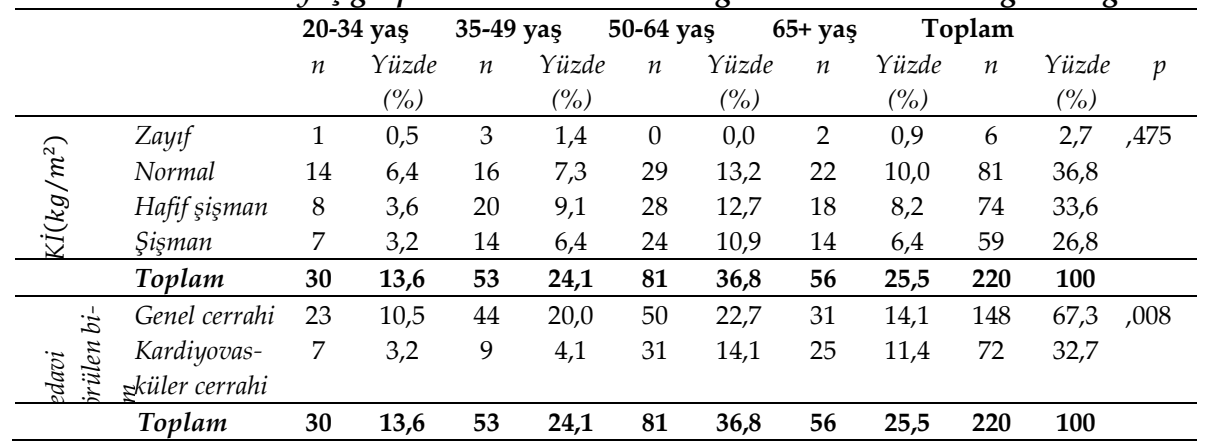

Tablo 3' de beslenme tarama araçlarından biri olan NRS-2002 ölçeğinde yer alan ön tarama sorularına verilen cevapların hastaların cinsiyetlerine göre dağılımı sunulmuştur. Buna göre çalışmaya katılan erkek hastaların $\% 5,5^{\prime}$ inin $(n=12)$, kadın hastaların \%2,3'ünün $(n=5)$, toplamda ise hastaların $\% 7,7^{\prime} \operatorname{sinin}(n=17)$ VKİ değeri $20,5 \mathrm{~kg} / \mathrm{m}^{2 \prime}$ den daha küçüktür. Cinsiyetler arasında VKİ açısından anlamlı bir farklılığın olup olmadığı Pearson'un ki-kare testi ile incelenmiş ve istatistiksel olarak anlamlı bir farklılık bulunamamıştır $(p=0,218>0,05)$. Aynı tabloya göre, son 3 ayda kilo kaybı yaşayan hastaların oranı \%47,3 $(n=104)$, son hafta gıda alımında azalma olan hastaların oranı da \%38,2 $(n=84)$ olarak bulunmuştur. Her iki durumda da cinsiyete göre istatistiksel olarak anlamlı bir farklığa rastlanılmamıştır ( $p=0,082>0,05, p=0,643>0,05)$. NRS-2002 ölçeği ön tarama sorularının içinde yer alan "Hasta ağır hasta konumunda mı?" sorusuna ilişkin değerler ise çalışmaya katılan hiçbir hastanın ağır hasta olmaması nedeniyle Tablo 3'e eklenmemiştir.

NRS 2002 beslenme tarama ölçeğinde toplam skor 3 ve üstü olduğunda beslenme riskinin mevcut olduğu, skor 3'ün altında olduğunda ise her hafta beslenme taramasının tekrarlanması ve önlem mahiyetinde beslenme planı uygulanması önerilmektedir. 
Tablo 3. NRS 2002 beslenme tarama ölçeğinin ön tarama sorularını cinsiyete göre dă̆ılımı

\begin{tabular}{|c|c|c|c|c|c|c|c|c|}
\hline \multirow{2}{*}{$\begin{array}{c}\text { NRS2002 Ön Tarama } \\
\text { Soruları }\end{array}$} & & \multicolumn{2}{|c|}{ Erkek } & \multicolumn{2}{|c|}{ Kadın } & \multicolumn{2}{|c|}{ Toplam } & \multirow[t]{2}{*}{$p$} \\
\hline & & $n$ & Yüzde $(\%$ & $n$ & $\begin{array}{l}\text { Yüzde } \\
(\%)\end{array}$ & $n$ & $\begin{array}{c}\text { Yüzde } \\
(\%)\end{array}$ & \\
\hline \multirow[t]{2}{*}{$V K \dot{I}<20,5 \mathrm{~kg} / \mathrm{m}^{2} \mathrm{mi} ?$} & Evet & 12 & 5,5 & 5 & 2,3 & 17 & 7,7 & \multirow[t]{2}{*}{0,218} \\
\hline & Hayır & 112 & 50,9 & 91 & 41,4 & 203 & 92,3 & \\
\hline \multirow[t]{2}{*}{ Son 3 ayda kilo kaybetti mi? } & Evet & 65 & 29,5 & 39 & 17,7 & 104 & 47,3 & \multirow[t]{2}{*}{0,082} \\
\hline & Hayır & 59 & 26,8 & 57 & 25,9 & 116 & 52,7 & \\
\hline \multirow{2}{*}{$\begin{array}{l}\text { Son hafta gida alımında } \\
\text { azalma oldu mu? }\end{array}$} & Evet & 49 & 22,3 & 35 & 15,9 & 84 & 38,2 & \multirow[t]{2}{*}{0,643} \\
\hline & Hayır & 75 & 34,1 & 61 & 27,7 & 136 & 61,8 & \\
\hline
\end{tabular}

Bu doğrultuda Tablo 4'deki ölçek puanları gruplandırıldığında toplam skoru 3 ve üstü olanlar çalışmaya katılanların \%22.8'ini oluştururken, skoru 3'ün altında olanlar ise katılımcıların \%77,2'sini oluşturmaktadır. Beslenme riski mevcut olan bireylerin cinsiyetlere göre dağılımına bakıldığında erkeklerin oranının \%15,5, kadınların oranının ise \%7,3 olduğu görülmektedir. Bu skorlara göre cinsiyetin beslenme riski üzerinde anlamlı bir farklılık yaratıp yaratmadığı Mann Whitney $U$ testi ile analiz edilmiş ve istatistiksel olarak anlamlı bir farklılık bulunmamıştır $(p=0,443>0,05)$.

Yaş gruplarına göre NRS 2002 skorlarının dağılımı incelendiğinde, 2034 yaş aralı̆̆ında hastaların $\% 3,6,65$ yaş ve üzerindeki hastaların ise $\% 8,2$ oranında beslenme riski olduğu belirlenmiştir. Ayrıca NRS skorlarına yaşın etkisi Kruskal Wallis testi ile analiz edilmiş ve yaş gruplarına göre beslenme riskinde anlamlı bir farklılık olduğu saptanmıştır $(p=0,004<$ $0,05)$. Bu farklılığında 65 yaş ve üzeri bireylerdeki beslenme riskinin diğer yaş gruplarına göre çok daha yüksek olmasıyla oluştuğu tespit edilmiştir.

Tablo 4'de VKİ değerlerine göre NRS 2002 skorlarının dağılımı incelendiğinde en yüksek risk skoru olan NRS:5 skorunda "zayıf (VKİ < $18,50)$ " ve "hafif şişman $(25<V K \dot{I}<29,99)$ " olarak değerlendirilen gruplarda 1'er hastanın olduğu diğer gruplarda ise kimsenin olmadığ1 görülmektedir. NRS skorlarının VKİ gruplarına göre istatistiksel olarak anlamlı bir farklılık gösterdiği yapılan Kruskal Wallis testi sonucunda tespit edilmiştir $(p=0,046<0,05)$. Beslenme riski açısından farklılı̆̆ oluşturan grubun ise "zayıf" hastaların oluşturduğu grup olduğu belirlenmiştir. 
Tablo 4. NRS 2002 beslenme tarama ölçeği puanlarmın demografik ve VKI'ye göre dă̆ılımı

\begin{tabular}{llllllllll}
\hline \multicolumn{2}{l}{ Değişkenler } & \multicolumn{9}{c}{ NRS 2002 ölçek puanları (\%) } & \multicolumn{3}{c}{ Ort. Rank } & $p$ \\
\cline { 3 - 9 } & & $\mathbf{0}$ & $\mathbf{1}$ & $\mathbf{2}$ & $\mathbf{3}$ & $\mathbf{4}$ & $\mathbf{5}$ & & \\
\hline Cinsiyet & Erkek & 7,7 & 16,8 & 16,4 & 10,5 & 4,1 & 0,9 & 113,27 & 0,443 \\
& Kadın & 1,8 & 19,5 & 15,0 & 5,9 & 1,4 & 0,0 & 106,92 & \\
\hline Yaş grubu & $20-34$ & 2,3 & 5,0 & 2,7 & 2,7 & 0,9 & 0,0 & 103,45 & 0,004 \\
& $35-49$ & 3,6 & 9,1 & 7,3 & 2,3 & 1,8 & 0,0 & 99,75 & \\
& $50-64$ & 3,2 & 16,4 & 10,5 & 5,9 & 0,9 & 0,0 & 102,40 & \\
\hline VKI & 65 ve üzeri & 0,5 & 5,9 & 10,9 & 5,5 & 1,8 & 0,9 & 136,17 & \\
& Zayıf & 0,0 & 0,5 & 0,9 & 0,5 & 0,5 &, 5 & 159,00 & 0,046 \\
& Normal & 3,6 & 10,9 & 11,8 & 6,8 & 3,6 & 0,0 & 118,86 & \\
& Hafif & 4,1 & 11,8 & 10,0 & 6,8 & 0,5 & 0,5 & 107,43 & \\
& Şişman & & & & & & & & \\
& Şişman & 1,8 & 13,2 & 8,6 & 2,3 & 0,9 & 0,0 & 97,95 & \\
\hline
\end{tabular}

MUST testinde toplam malnütrisyon riski skoru 0 olduğunda 'düşük risk', 1 olduğunda 'orta risk', 2 ve üzeri olduğunda ise 'yüksek risk' olarak değerlendirilmektedir. Bu çalışmada en yüksek MUST risk skoru olan 4 puan düzeyinde kadın hasta bulunmazken, toplam bireylerin \%1,8'ine karşılık gelen 4 erkek hasta bu puan seviyesindedir (Tablo 5). Cinsiyete göre MUST test skorlarının farklılık gösterme durumu Mann Whitney U testi ile analiz edilmiş ve erkeklerin beslenme riskinin kadınlara göre daha yüksek olduğu görülmüştür $(p=0,024)$. Yaş gruplarına göre MUST test skorları arasında istatistiksel olarak anlamlı bir farklılığın bulunmadığı Kruskal Wallis testi ile görülmüsstür $(p=0,960)$. VKİ gruplarına göre MUST test skorlarına bakıldığında 'zayıf' olan grubun tamamının beslenme riski taşıdı̆̆ı ve ortalama rank $(209,42)$ değerine bakıldığında diğer gruplardan farklılığının istatistiksel olarak anlamlı olduğu yapılan analiz sonucunda belirlenmiştir $(p<0,001)$.

Çalışma kapsamındaki tüm bireylerin NRS 2002 ve MUST beslenme durumu ölçeklerine göre elde edilen skorları Tablo 6'da sunulmuştur. Çalışmada kullanılan ölçekler arasında uyum analizi yapılabilmesi için NRS 2002 ölçeğine yeniden gruplandırma yapılarak 3 alt gruba ayrılmıştır.

Bu gruplama, NRS 2002 ölçek skoru 0 ve 1 olanlar için 'düşük risk', 2 olanlar için 'orta risk', 3 ve üstü olanlar için de 'yüksek risk' şeklinde ifade edilmiştir. NRS 2002 skorlarına göre bireylerin \%45,9'u iyi beslenme durumunda yani "düşük risk" grubunda iken, MUST skorlarına 
bakıldığında bireylerin \%59,5'inin "düşük risk" gurubunda olduğu görülmektedir.

Tablo 5. MUST beslenme tarama testi puanlarının demografik ve VKI'ye göre dağılımı

\begin{tabular}{lllrrrrrr}
\hline Değişkenler & \multicolumn{6}{c}{ MUST testi puanları (\%) } & Ort. Rank & $p$ \\
\cline { 2 - 8 } & & 0 & 1 & 2 & 3 & 4 & & \\
\hline Cinsiyet & Erkek & 30,0 & 13,6 & 8,6 & 2,3 & 1,8 & 117,99 & 0,024 \\
& Kadın & 29,5 & 7,7 & 5,5 & 0,9 & 0,0 & 100,82 & \\
\hline Yaş grubu & $20-34$ & 7,7 & 3,2 & 2,3 & 0,5 & 0,0 & 113,00 & 0,960 \\
& $35-49$ & 15,5 & 2,7 & 2,7 & 2,3 & 0,9 & 110,19 & \\
& $50-64$ & 20,9 & 9,1 & 6,4 & 0,0 & 0,5 & 111,98 & \\
& 65 ve üzeri & 15,5 & 6,4 & 2,7 & 0,5 & 0,5 & 107,31 & \\
\hline VKİ & Zayıf & 0,0 & 0,0 & 0,9 & 0,5 & 1,4 & 209,42 & 0,000 \\
& Normal & 16,8 & 10,9 & 6,4 & 2,3 & 0,5 & 125,45 & \\
& Hafif şişman & 21,8 & 7,3 & 4,1 & 0,5 & 0,0 & 102,80 & \\
& Şişman & 20,9 & 3,2 & 2,7 & 0,0 & 0,0 & 89,58 & \\
\hline
\end{tabular}

Bireylerin \%31,4'ü NRS 2002 skorlarına göre 'orta risk" grubunda iken, MUST skorlarına göre \%21,4'ü 'orta risk' grubunda yer almaktadır.

Tablo 6. Katılımcıların NRS 2002 ve MUST testlerine göre beslenme risklerinin karşılaştırılması

\begin{tabular}{lccccccccc}
\hline & \multicolumn{2}{c}{$\begin{array}{c}\text { Düşük Risk } \\
\text { (NRS: } 0+1)\end{array}$} & \multicolumn{2}{c}{$\begin{array}{c}\text { Orta Risk } \\
\text { (NRS: 2) }\end{array}$} & \multicolumn{2}{c}{$\begin{array}{c}\text { Yüksek Risk } \\
\text { (NRS: 3+4+5) }\end{array}$} & Toplam & $p$ \\
& $\begin{array}{c}\text { Yüzde } \\
(\%)\end{array}$ & $n$ & $\begin{array}{c}\text { Yüzde } \\
(\%)\end{array}$ & $n$ & $\begin{array}{c}\text { Yüzzde } \\
(\%)\end{array}$ & $n$ & $\begin{array}{c}\text { Yüzde } \\
(\%)\end{array}$ & $n$ & \\
\hline $\begin{array}{l}\text { Düşük Risk } \\
\text { (MUST =0) }\end{array}$ & 40,9 & 90 & 14,5 & 32 & 4,1 & 9 & 59,5 & 131 & $<0,001$ \\
$\begin{array}{l}\text { Orta Risk } \\
\text { (MUST = 1) }\end{array}$ & 4,1 & 9 & 9,1 & 20 & 8,2 & 18 & 21,4 & 47 & \\
$\begin{array}{l}\text { Yüksek Risk } \\
\text { (MUST=2+3+4) }\end{array}$ & 0,9 & 2 & 7,7 & 17 & 10,5 & 23 & 19,1 & 42 & \\
\hline Toplam & $\mathbf{4 5 , 9}$ & $\mathbf{1 0 1}$ & $\mathbf{3 1 , 4}$ & $\mathbf{6 9}$ & $\mathbf{2 2 , 7}$ & $\mathbf{5 0}$ & $\mathbf{1 0 0 , 0}$ & $\mathbf{2 2 0}$ & \\
\hline
\end{tabular}

Son olarak NRS 2002'ye göre bireylerin \%22,7'si 'yüksek risk' grubunda yer alırken, MUST testine göre 'yüksek risk' grubundakilerin oranı \%19,1 olarak hesaplanmıştır. Elde edilen bu bilgilere göre NRS 2002 ve MUST beslenme kalitesi belirleme ölçekleri arasında, beslenme durumlarının dağılımı yönünden istatistiksel açıdan anlamlı bir uyum olduğu yapılan kappa analizi sonucunda tespit edilmiştir $(\mathrm{k}=0,358, p<$ $0,001)$. Ayrıca iki test skoru arasındaki korelasyon incelendiğinde de, NRS 2002 skorları ile MUST skorları arasında istatistiksel olarak anlamlı pozitif 
yönlü ve orta düzeyde bir ilişkinin olduğu görülmektedir $(r=0,589, p<$ $0,001)$. Bu durumda da yatan hastalarda hem MUST hem NRS-2002 tarama testlerinin kullanılabileceği düşünülmektedir.

\section{Sonuç ve Öneriler}

Bu çalışma yaş ortalaması 53,75 olan 124 erkek ve yaş ortalamaları 53,09 olan 96 kadın gönüllü katılımcı hasta ile gerçekleştirilmiştir. Cinsiyete göre yaş grupları açısından bir farkın olup olmadığı ki-kare testi ile test edilmiş ve istatistiksel olarak anlamlı bir farklılık bulunamamıştır ( $p=$ $0,988>0,05)$. Bireylerin tedavi görmekte olduğu kliniklere göre cinsiyet dağılımına bakıldığında ise, genel cerrahi ile ilgili hastalığı olan erkeklerin oranının \%34,5, kadınların oranının \%32,7 olduğu görülürken, kardiyovasküler ile ilgili hastalığı olan erkeklerin oranının \%21,8, kadınların oranının ise \%10,9 olduğu belirlenmiştir.

VKİ grupları arasında bireylerin cinsiyetleri açısından farklılık gösterip göstermediği olabilirlik oran testi ile analiz edilmiş ve aralarında istatistiksel olarak anlamlı bir farklılık olduğu tespit edilmiştir $(p=0,001)$. Bu farkın nereden kaynaklandığını belirlemek amacıyla yapılan çoklu karşılaştırmalara göre, 'şişman' olarak ifade edilen değer aralığındaki kadınların oranının erkeklere göre daha yüksek olduğu bulunmuştur.

NRS 2002 ön tarama sorularına göre, cinsiyetler arasında VKI'nin $20,5 \mathrm{~kg} / \mathrm{m}^{2 \prime}$ den küçük olup olmaması açısından anlamlı bir farklılığın olup olmadığı Pearson'un ki-kare testi ile incelenmiş ve istatistiksel olarak anlamlı bir farklılık bulunamamıştır $(p=0,218>0,05)$. Ayrıca son 3 ayda kilo kaybı yaşayan hastaların oranı $\% 47,3$, son hafta gıda alımında azalma olan hastaların oranı da \%38,2 olarak bulunmuş ve her iki durumda da cinsiyete göre istatistiksel olarak anlamlı bir farklığa rastlanılmamiştır $(p=0,082>0,05, p=0,643>0,05)$.

NRS 2002 ölçek puanları gruplandırıldığında, cinsiyetin beslenme riski üzerinde anlamlı bir farklılık yaratıp yaratmadığı Mann Whitney $U$ testi ile analiz edilmiş ve istatistiksel olarak anlamlı bir farklılık bulunmamıştır $(p=0,443>0,05)$. NRS skorlarına yaşın etkisi Kruskal Wallis testi ile analiz edilmiş ve yaş gruplarına göre beslenme riskinde anlamlı bir farklılık oluştuğu sonucuna ulaşılmıştır $(p=0,004<0,05)$. Bu farklılığın da 65 yaş ve üzeri bireylerdeki beslenme riskinin diğer yaş gruplarına göre çok daha 
yüksek olmasıyla oluştuğu tespit edilmiştir. Ayrıca NRS skorlarının VKİ gruplarına göre istatistiksel olarak anlamlı bir farklılık gösterdiği yapılan Kruskal Wallis testi sonucunda tespit edilmiştir $(p=0,046<0,05)$. Beslenme riski açısından farklılığı oluşturan grubun da "zayıf" olarak isimlendirilen bireylerin oluşturduğu grup olduğu belirlenmiştir.

Cinsiyete göre MUST test skorlarının farklılık gösterme durumu Mann Whitney $\mathrm{U}$ testi ile analiz edilmiş ve erkeklerin beslenme riskinin kadınlara nazaran daha yüksek olduğu görülmüştür $(p=0,024<0,05)$. Yaş gruplarına göre MUST test skorları arasında istatistiksel olarak anlamlı bir farklılığın bulunmadığı Kruskal Wallis testi ile görülmüştür $(p=0,960>$ 0,05). VKİ gruplarına ait MUST test skorlarına bakıldığında 'zayıf' olan grubun tamamının beslenme riski taşıdığı ve ortalama rank $(209,42)$ değerine bakıldığında diğer gruplardan farklılığının istatistiksel olarak anlamlı olduğu yapılan analiz sonucunda belirlenmiştir $(p<0,001)$.

Çalışmada kullanılan ölçekler arasında uyum analizi yapılabilmesi için NRS 2002 ölçeğine yeniden gruplandırma yapılarak 3 alt gruba ayrılmıştır. Bu gruplama, NRS 2002 ölçek skoru 0 ve 1 olanlar için 'düşük risk', 2 olanlar için 'orta risk', 3 ve üstü olanlar için de 'yüksek risk' şeklinde ifade edilmiştir. Bu doğrultuda elde edilen bilgilere göre NRS 2002 ve MUST beslenme kalitesi belirleme ölçekleri arasında, beslenme durumlarının dağılımı yönünden istatistiksel açıdan anlamlı bir uyum olduğu yapılan kappa analizi neticesinde tespit edilmiştir $(\mathrm{\kappa}=0,358, p<$ $0,001)$. Ayrıca iki test skoru arasındaki korelasyon incelendiğinde de, NRS 2002 skorları ile MUST skorları arasında istatistiksel olarak anlamlı pozitif yönlü bir ilişkinin olduğu görülmektedir $(r=0,592, p<0,001)$.

Malnütrisyona zamanında müdahale açısından nütrisyon taraması, malnütrisyonu bulunan ve malnütrisyon riski taşıyan bireylerin saptanmasında en basit ve kolay yöntemlerden biridir. Bu nedenle hastanelerde ve tüm sağlik kuruluşlarında tarama testlerinin rutin kullanımına ilişkin protokoller oluşturulmalıdır. Klinik hemşireleri ve tıbbi personel tarafından kolayca gerçekleştirilebilecek ve hastaneye yatıştan sonra ilk 24-48 saat içinde yapılacak olan bir nütrisyon taraması, malnütrisyon riski bulunan hastaların belirlenmesi ve gereken önlemlerin multi-disipliner bir ekip tarafından alınması açısından çok önemlidir. İdeal olarak bir tarama aracının bütün malnütrisyonlu hastaları ve risk altındaki hastaları bir taramayla tanımlaması istenir, ancak bu konuda 
altın bir standart yoktur. Bu çalışmada da toplanan tüm veriler değerlendirildiğinde, yatan hastaların nütrisyon taramasında kullanılan MUST tarama testi ile NRS-2002 arasında bir uyumun olduğu ve testler arasında anlamlı bir farklılığın olmadığı görülmüştür. Öncelikli olarakta halihazırdaki klinik hastalık, son dönemde yaşanan kilo kaybı, son bir haftadaki beslenme durumu, VKİ değeri, hastanın genel görünümü ve yaşı belirlenerek puanlama yapılması gerekliliği ve yatan hastalarda hem MUST hem NRS-2002 tarama testlerinin kullanılabileceği görülmüştür. 


\title{
EXTENDED ABSTRACT
}

\section{Comparison of Nutrision Risk Assessment Scales with Statistical Tests}

\author{
* \\ Selim Gündüz - Dilek Doğan - Ezgi Bayraktar \\ Adana Scienceve Technology University - Adana Education ve Research Hospital
}

Nutrition is known to protect individuals from diseases, as well as the course of the disease in the treatment process. Especially in individuals with severe disease, the disease itself and the treatments applied may cause nutritional disorders at various levels. If the prevention of these nutritional disorders is not taken, the treatment processes of the patients are adversely affected, their quality of life decreases and even the risk of death increases. Because the malnutrition that develops in such patients delays the healing process of the wounds in the body, prolongs the hospital stay, causes the formation of infections and decreases the body's resistance to the side effects of the treatments due to the weakening of the immune system.

With the prevalence of malnutrition in hospitalized patients in Turkey, it was observed that there was not enough data or easy access to this issue. However, in related studies, it was found that malnutrition in patients with varying rates of $5-60 \%$ at the time of admission, while the incidence of malnutrition was higher in all age groups, but was higher in the age group of 65 years and older. When the relevant studies in this area are examined, it is seen that the risk is higher in the patients who applied to the intensive care unit and medical oncology compared to the patients who applied to other departments.

The aim of this study is to compare the results of MUST (Malnutrition Universal Screening Tool) and NRS-2002 (Nutritional Risk Screening 2002) nutritional screening scales which are widely used in nutritional risk assessment of inpatients and to investigate the harmony between them statistically. This study was carried out with a total of 220 people (124 male, 96 female) between the ages of 20 and 90 who were being treated in 
Republic of Turkey Ministry Of Health Adana Provincial Health Directorate Adana City Training and Research Hospital. Questionnaires applied to the participants include demographic questions (gender, age, etc.), anthropometric measurements (height, weight, etc.) and questions found on the NRS-2002 and MUST nutrition screening scales. The Kappa analysis was used to determine whether there was a correlation between NRS-2002 and MUST tests for the distribution of nutritional status of individuals. In addition, the results obtained from dietary screening scales and whether there was a statistically significant difference between the demographic characteristics of the patients were analyzed with non-parametric statistical methods, Mann Whitney $U$ and Kruskal Wallis tests. While the mean age of the men who participated in the study was 53.75 and the body mass index was 25.64, the mean age of women was 53.09 and the mean body mass index was 28.86 . According to the NRS-2002 nutrition screening scale, while $22.3 \%(n=49)$ of the individuals who participated in the study had a nutritional risk ,77.7\% $(\mathrm{n}=171)$ of the individuals who participated in the study had no significant risk related to nutrition. According to the MUST test, while $60 \%(n=132)$ of the individuals had no sign of a significant risk of nutrition, $20.9 \%(n=46)$ of the individuals had moderate risk and $19.1 \%(n=42)$ of the individuals had a high degree of risk.

NRS 2002 was re-grouped into 3 sub-groups in order to carry out compliance analysis among the scales used in the study. This grouping is expressed as ve low risk edil for those with NRS 2002 scale score 0 and 1, olan medium risk risk for those with 2, and 0 high risk risk for those 3 and above. According to the information obtained in this direction, NPS 2002 and MUST were determined as a result of the kappa analysis, which was found to be statistically significant in terms of distribution of nutritional status between the determination of feeding quality $(\mathrm{Bu}=0.358, \mathrm{p}<0.001)$. In addition, when the correlation between the two test scores was examined, it was observed that there was a statistically significant positive relationship between NRS 2002 scores and MUST scores $(\mathrm{r}=0.592, \mathrm{p}<0.001)$. As a result, there was a positive correlation between NRS-2002 and MUST nutrition screening tests applied to individuals and there was a statistically significant correlation between the samples used in this study. 
Nutritional screening in terms of timely intervention to malnutrition is one of the simplest and easiest methods for detecting malnourished and malnourished individuals. Therefore, protocols for routine use of screening tests should be established in hospitals and all health institutions. A nutritional screening that can be easily performed by clinical nurses and medical personnel and performed within the first $24-48$ hours after hospitalization is crucial to identify patients with a risk of malnutrition and to take necessary measures by a multidisciplinary team. Ideally, a screening tool is required to identify all malnutrition patients and patients at risk with a screening, but there is no gold standard. When all the data collected in this study were evaluated, it was observed that there was a correlation between the MUST screening test used in nutritional screening of inpatients and NRS-2002 and there was no significant difference between the tests. Mainly available clinical disease, weight loss in recent months, nutritional status in the last week, body mass index $(<18.5)$, general status and age required to be questioned by scoring and MUST and NRS-2002 screening tests in inpatients can be used.

\section{Kaynakça / References}

Bendich, A. (2009). Fundamentals of nutrition and geriatric syndromes. Bales, C.W., Ritchie, C.S., Wellman, N.S.(Ed.) Handbook of Clinical Nutrition and Aging (s.65-235). New York Humana Press.4

Bolayır, B. (2014). Hospitalize hastalarda nutrisyonel değerlendirme testi NRS2002'nin (Nutritıonal Risk Screening-2002) geçerlilik ve güvenilirliğinin değerlendirilmesi. Yayımlanmamış Uzmanlık Tezi, Hacettepe Üniversitesi, Tıp Fakültesi, İç Hastalıkları Anabilim Dalı, Ankara.

Bonnefoy, M., Jauffret, M., Kostka, T., ve Jusot, J. F. (2002). Usefulness of calf circumference measurement in assessing the nutritional state of hospitalized elderly people. Gerontology, 48(3), 162-169.

Cederholm, T., Barazzoni, R., Austin, P., Ballmer, P., Biolo, G., Bischoff, S. C., ve Jensen, G. L. (2017). ESPEN guidelines on definitions and terminology of clinical nutrition. Clinical Nutrition, 36(1), 49-64. 
Dervişoğlu, A., Tümer, G., Canbaz, S., Şenyürek, G., ve Malazgirt, Z. (2006). Cerrahi hastalarda malnütrisyon riski ve beslenme değerlendirilmesinde kullanılan farklı yöntemlerin karşılaştırılması. Türkiye Klinikleri Cardiovascular Sciences, 18(3), 206-210.

Elia M. (2003). Chairman and Editor. Screening for Malnutrition: A Multidisciplinary Responsibility. Development and Use of the 'Malnutrition Universal Screening Tool' ('MUST') for Adults. Malnutrition Advisory Group (MAG), a Standing Committee of BAPEN. Redditch, Worcs.: BAPEN.

Gündoğdu H. (2010). Malnütrisyon. Türk İç Hastalıkları Uzmanlık Derneği. İ̧ Hastalıkları Dergisi, 17, 189-202.

Kaya, Ş. A. (2015). Farklı beslenme tarama testleri kullanılarak ameliyat öncesi gastrointestinal sistem kanserli hastalarm beslenme durumunun değerlendirilmesi. Yayımlanmamış Yüksek Lisans Tezi, Hacettepe Üniversitesi Sağlık Bilimleri Enstitüsü, Ankara.

Kondrup J, Rasmussen HH, Hamberg O, Stanga Z, Group AHEW. (2003). Nutritional risk screening (NRS 2002): A new method based on an analysis of controlled clinical trials. Clin Nutr. 22(3), 321-336.

Kondrup, J., Allison, S.P., Elia, M., Vellas, B., Plauth, M. (2003). ESPEN Guidlines fo Nutrition Screening-2002. Clinical Nutrition, 22(4), 415-421.

Korfali G, Gündoğdu H, Aydintuğ S, et al. (2009). Nutritional risk of hospitalized patients in Turkey. Clin Nutr. 28(5), 533-537.

Kömürcü, Ş. (2004). Baş ve Boyun Kanserli Hastalarda Beslenme Problemi. KBB ve BBC Dergisi, 2(12), 101-108.

Lim, S.L., Ong, K.C.B., Chan, Y.H., Loke, W.C., Ferguson, M.,Daniels, L.(2012) Malnutrition and its impact on cost of hospitalization, length of stay, readmission and 3-year mortality. Clinical Nutrition, 31(3), 345-350.

Pekcan, G. (2011). Beslenme Durumunun Saptanması. A. Baysal ve e. al. (Ed.). Diyet el kitabı (c. 5, s. 67-142). Ankara: Hatipoğlu Basım ve Yayım San. Tic. Ltd. Şti.

Pirlich M, Schütz T, Kemps M, Luhman N, Minko N, Lübke HJ, et al. (2005). Social risk factors for hospital malnutrition. Nutrition, 21, 295-300. 
Norman, K., Pichard, C., Lochs, H., Pirlich, M. (2008). Prognostic impact of disease-related malnutrition. Clinical Nutrition, 27(1), 5-15.

Sobotka, L., ve Allison, S. P. (Eds.). (2011). Basics in clinical nutrition. Galen.

Sungurtekin, H., Sungurtekin, U., Hanci, V., ve Erdem, E. (2004). Comparison of two nutrition assessment techniques in hospitalized patients. Nutrition, 20(5), 428-432.

Yentür, E. (2011). Beslenme durumunun değerlendirilmesi. Klinik Gelişim, 24, 1-4.

\section{Kaynakça Bilgisi / Citation Information}

Gündüz, S., Doğan, D. ve Bayraktar, E. (2019). Nutrisyonel risk değerlendirme ölçeklerinin istatistiksel testlerle karşılaştırılması. OPUS-Uluslararası Toplum Araştırmaları Dergisi , 10(17), 815-834. DOI: 10.26466/opus.523493 